\title{
Editorial
}

\section{Is there Risk when Prescribing Isotretinoin to Pilots: Might the Use of Isotretinoin Rule Out a Career in Flying?}

\author{
Craig G. Burkhart ${ }^{*}, 1$ and Craig N. Burkhart ${ }^{2}$ \\ ${ }^{I}$ University of Toledo College of Medicine, USA \\ ${ }^{2}$ Department of Dermatology, Northwestern University, Chicago, Illinois, USA
}

Besides females getting pregnant, there is now a new potential risk of persons taking isotretinoin, namely, being banned from certain professions, such as piloting airplanes.

Presently, the Civil Aviation Authority in the United Kingdom completely contraindicates pilots from flying while on isotretinion [1]. Additionally, following a month off the drug, an English pilot is required to have formal ophthalmologic assessment by the Civil Aviation Authority. The guidelines for flight surgeons in Canada restricts pilots to A3 category in which pilots using isotretinoin are restricted to fly with or as copilot only. The Federal Aviation Administration in the United States has restrictions that persons on the drug are not approved for night flying, but is presently reviewing if more restrictions are appropriate.

To be sure, ocular side effects can occur with isotretinoin, such as abnormal meibomian gland secretion, sicca, blepharoconjunctivitis, decreased tolerance to contact lenses, photophobia, and keratitis. However, such problems are short-lived and resolve spontaneously on discontinuation of the drug. There are some concerns regarding potentially persistent abnormalities such as corneal opacities, raised intracranial pressure, and retinal abnormalities, specifically night blindness. By electroretinograms, defects in night vision have been detected despite absence of subjective complaints by patients [2]. Moreover, such abnormalities have been demonstrated to persist as long as 8 years after cessation of isotretinoin $[3,4]$. Indeed, there is now a query in the medical literature whether even one-time use of isotretinoin rules out a career in flying [4].
Of concern is if someone who has taken isotretinoin is ruled ineligible for commercial flying for life, might other professions which good night vision is required, such as truck driving, and ambulance drivers also become restrictive? Indeed, the Driver and Vehicle Licensing Agency may also eventually have a specific policy on the use of isotretinoin.

Inasmuch as isotretinion may affect night vision by interfering with the retinol pathway essential to the function of photoreceptors, it would be prudent for studies to be initiated to assess whether lower doses of isotretinion can be utilized without compromising night vision. Especially in light that dosing of isotretinion even at $10 \mathrm{mg}$ per day for the 5-month duration of therapy is almost equally effective as $1-2 \mathrm{mg} / \mathrm{kg}$ dosing by some observers [5], we must proceed to protect the interests (and future possible occupations) of our patients who need the drug before additional restrictions and limitations are unwisely applied.

\section{REFERENCES}

[1] Taibjee SM, Charles-Holmes R. Pitfalls of prescribing acne therapies including isotretinoin for pilots. Int $\mathrm{J}$ Dermatol 2008; 158: 653-6.

[2] Brown RD, Grattan CEH. Visual toxicity of synthetic retinoids. $\mathrm{Br}$ J Ophthalmol 1989; 73: 286-8.

[3] Weleber RG, Denman ST, Hanifin JM, Cunningham WJ. Abnormal retinal function associated with isotretinoin therapy for acne. Arch Ophthalmol 1986; 104: 831-7.

[4] Mollan SP, Woodcock M, Siddiqi R. Does use of isotretion rule out a career in flying? Br J Ophthalomol 2006; 90: 857-8.

[5] Burkhart CG. Second vote for accutane's low dosing. Dermatology Times 2003; 24(9): 8 .

*Address correspondence to this author at the 600 Monroe Street, Suite 106B, Sylvania, Ohio 43560, USA; cgbakb@aol.com. 